\title{
Ascertaining the degradation state of ceramic tiles: A preliminary non-destructive step in view of conservation treatments
}

\author{
Teresa P. Silva $^{\text {a,* }}$, Maria-Ondina Figueiredo ${ }^{\text {a,b, },}$, Maria-Isabel Prudêncio ${ }^{c, 2}$ \\ a LNEG, Unity of Mineral Resources and Geophysics, Apt. 7586, 2610-999 Amadora, Portugal \\ b CENIMAT/I3N, Mat. Sci. Dept., Fac. Sci. Technol., New Univ. Lisbon, 2829-516 Caparica, Portugal \\ ' ITN/IST, Nuclear and Technologic Institute, Technical University of Lisbon, EN 10, 2686-953 Sacavém, Portugal
}

\section{A R T I C L E I N F O}

\section{Article history:}

Received 27 September 2012

Received in revised form 31 May 2013

Accepted 6 June 2013

Available online 6 July 2013

\section{Keywords:}

Ceramic tiles

16th-18th century polychrome glazes

Non-destructive characterization

$\mathrm{X}$-ray techniques

\begin{abstract}
A B S T R A C T
Conserving the cultural heritage is a general concern and the use of non-destructive techniques to characterize ancient materials is important. Serious deterioration effects in environmentally exposed ancient glazed ceramic tiles arise from the development of micro-organisms (algae/fungi) within the pore system. Subsequent biodegradation processes are particularly harmful once the decorated glaze is damaged by exfoliation/detachment. Three case studies will be addressed: Portuguese polychrome decorated tiles from the interior of two churches (16th-17th century) and from the outdoor of a Palace (18th century). Small tile fragments were directly irradiated in a wavelength-dispersive X-ray fluorescence spectrometer for glaze chemical characterization and subsequently irradiated in a powder diffractometer to assess the phase constitution of both glaze and ceramic body. Cleaning and conserving these ancient cultural artifacts involve a decontamination process applying innovative non-destructive techniques. The present work is intended as a contribution to diagnose the actual degradation state of ancient tiles in view of future decontamination actions using gamma radiation.
\end{abstract}

(c) 2013 Elsevier B.V. All rights reserved.

\section{Introduction}

Glazed ceramic tiles ("azulejos" in Portuguese) deserve particular attention due to their wide application in important public buildings like churches or palaces for esthetic purposes. Attractive tiles placed inside and/or outside the edifice - most of them built some hundred years ago - constitute an important patrimony within cultural heritage that is important to preserve.

Ancient panels exposed to environmental conditions are liable to the development of various pathologies that could give rise to tile degradation: in outside panels the degradation is mainly due to the action of the sun, rain, air currents and humidity while inside the buildings, liquid water and vapor ascending through the porous system of the ceramic body may give rise to a network of fissures ("craquelé") and to glaze detachment, formation/efflorescence of salts or even development of micro-organisms (algae/fungi) that are particularly harmful on decorated glazes (Figueiredo et al., 2009).

When undertaking a restoration procedure, the choice of products and techniques for consolidation is critical for the restored tile durability. Although polymeric materials (e.g. Paraloid B-72) have nowadays a wide

\footnotetext{
* Corresponding author at: LNEG, Unity of Mineral Resources and Geophysics, Apt. 7586, 2610-999 Amadora, Portugal. Tel.: +351 214705 423; fax: + 351214718940 .

E-mail addresses: teresa.pena@lneg.pt (T.P. Silva), ondina.figueiredo@lneg.pt

(M.-O. Figueiredo), iprudenc@itn.pt (M.-I. Prudêncio).

${ }^{1}$ Tel.: +351214 705 415; fax: +351214718940

2 Tel.: + 351219946000
}

use in ceramic tiles conservation, the effect of the consolidation treatment on water absorption properties still requires further study (Vaz et al., 2008). The impregnation efficiency attained with different methods of consolidant application was recently approached through the visualization of the glazed tile inner structure by applying neutron tomography (Prudêncio et al., 2012).

The occurrence of stains in the glaze surface of ceramic tiles due to the presence of micro-organisms requires a quite different approach. Dark tarnishing on 19th century polychrome tile glazes was ascribed to the simultaneous presence of Cyanophyta and Bacillariophyta algae (Oliveira et al., 2001) but other micro-organisms (algae/fungi) may give rise to green stains, particularly in blue-and-white glazes from the 16th to the 18th century (Figueiredo, 2003; Silva et al., 2011).

Recently, new methodologies for decontamination based on the use of gamma radiation were successfully applied to art objects made of wood and paper (Rizzo et al., 2009; Severiano et al., 2010) and the need for a careful study of materials composition, prior to the treatment, was claimed.

The present work aims at characterizing in detail the degradation state of decorated tiles - produced in the 16th-18th century. Their glazes are lead-rich calco-sodic silica glasses, with tin oxide as opacifier (Figueiredo et al., 2002) - and their characterisation can be considered as a preliminary non-destructive step in view of conservation treatments using gamma radiation. Accordingly, non-destructive techniques based on X-ray characterization methodologies were applied by directly irradiating small tile fragments: diffraction (XRD) to identify the constituting 